\title{
ARTICLES
}

\section{KNOWLEDGE REGARDING INHALERS AMONG PATIENTS WITH BRONCHIAL ASTHMA}

Mr. Jayachandran, T. *|Dr. Suvarnaletha Devi **

*Ph.D Scholar, University of Kerala, Thiruvananthapuram Kerala, India **Professor cum Principal, Ananthapuri College of Nursing, Thiruvananthapuram, Kerala, India DOI: http://doi.org/10.47211/idcij.2020.v07i03.008

Received $15^{\text {th }}$ May 2020, Accepted 30 ${ }^{\text {th }}$ May 2020, Available online $10^{\text {th }}$ July 2020.

\begin{abstract}
There has been a sharp increase in the global prevalence, morbidity, mortality, and economic burden associated with asthma over the last 40 years, particularly in children. Approximately 300 million people worldwide currently have asthma, and its prevalence increases by 50\% every decade. Background: Proper inhaler use is important to asthma treatment and management. Asthma sufferers and people with other respiratory conditions who have been prescribed inhalers must know how to use them properly in times of emergency or for everyday treatment. Learning and practicing proper inhaler techniques can make a big difference in maintaining good respiratory health. Therefore is this study. Aim: To find the knowledge about inhaler use among patients with bronchial asthma. Study design: One group, pre-test-post-test, quasi experimental research design was used. Setting: The study was conducted at SP Multi Speciality Hospital, Trivandrum. Subjects: 400 adult Asthma patients, older than 18 years of age, diagnosed at least 6 months ago, receiving inhaler medications, able and willing to participate in the study. Tools: Tools used for the study were knowledge questionnaire and structured educational programme. Results: The total mean score of knowledge about inhaler use increased significantly from 14.40; SD 3.641 (pre-test) to 19.31; SD 3.943 (post test). Conclusion and Recommendation: Teaching the patients regarding appropriate use of devices can be crucial. All patients should receive appropriate instruction and guidance on effective technique when prescribed inhaler devices and this should be regularly reinforced.
\end{abstract}

KEYWORDS: Bronchial Asthma, Knowledge, Inhalers. 


\section{INTRODUCTION}

Asthma is a disorder of the bronchial airways characterised by periods of reversible bronchospasm. Asthma is often called reactive airway disease. This complex disorder involves biochemical, immunological, endocrine, infectious, autonomic and psychological factors.

Asthma is defined as chronic inflammatory disease of the airways characterised by airway hyper responsiveness to a variety of stimuli. It is manifested as a variable airway obstruction that resolves either spontaneously or after bronchodilator administration. Based on symptoms and lung function, the National Asthma Education and Prevention Program NAEPP has classified asthma as mild intermittent, mild persistent and moderate persistent.

\section{NEED AND SIGNIFICANCE OF THE STUDY}

Asthma affects school attendance, occupational choices, physical activity and other quality of life issues. The significant morbidity rates related to asthma may be attributed to limited access to health care, an inaccurate assessment of disease severity, a delay in seeking help, inadequate medical treatments, non adherence to prescribed therapy (especially anti inflammatory therapy), and an increase in allergens in the environment, especially in the inner city.

The increasing number of hospital admissions for asthma, which are most pronounced in young children, reflect an increase in severe asthma, poor disease management and poverty. Worldwide, approximately 180,000 deaths annually are attributable to asthma, although overall mortality rates have fallen since the 1980s.

Regular inhaled corticosteroids (ICS) are the mainstay of treatment of asthma. Even in case of mild disease in older adults, regular preventive treatment should be considered, given the poor perception of bronchoconstriction by older asthmatic patients. If symptoms persist despite ICS, addition of long-acting beta (2)-adrenoceptor agonists (LABA) should be considered. Addition of LABA to ICS improves asthma control and allows reduction in ICS dose. Long-term trials evaluating beta (2)-adrenoceptor agonists and other bronchodilator strategies are needed particularly in the elderly and in patients with cardiovascular comorbidities. There is no evidence that addition of anticholinergics improves control of asthma further, although the role of long-acting anticholinergics in the prevention of disease progression is currently being researched. Older patients need to be taught good inhaler technique to improve delivery of medications to lungs, minimise adverse effects and reduce the need for oral corticosteroids. Nurse-led education programmes that include a written asthma self-management plan have the potential to improve outcomes.

There is a confusing array of inhaler devices and drug/ device combinations available and it can be difficult for a clinician to make informed prescribing decisions about all the possible permutations. Current evidence suggests that there is no difference in the effectiveness of nebulisers and alternative inhaler devices compared to standard Pressurised Metered-Dose Inhalers (pMDIs) with or without a spacer device. As both pMDIs and dry powder inhalers are cheaper than nebulisers, a stepped approach to treatment would seem justified. pMDIs (with or without a spacer), or the cheapest inhaler device the patient can use adequately, should be prescribed as first-line treatment in all adults and children with stable asthma or COPD. The effectiveness of inhaler devices depends on more than just the devices themselves.

\section{PROBLEM STATEMENT}

\section{'A Study to Assess Knowledge regarding Inhalers among Patients with Bronchial Asthma' OBJECTIVES}

1. Assess knowledge regarding inhalers among patients with bronchial asthma.

2. Assess the effectiveness of structured educational programme on knowledge of inhalers among patients with bronchial asthma.

\section{RESEARCH METHODOLOGY}

Research Approach: The approach adopted is quasi experimental approach

Research Design: One group pre-test- post test design is adopted for the present study.

Setting of the study: The present study was conducted in SP Multi Speciality Hospital Trivandrum.

Population: The population for this study is all patients with bronchial asthma who is under inhaler treatment in Trivandrum district.

Sample: The sample consists of patients with bronchial asthma under inhaler treatment.

Sampling technique: The investigator used purposive sampling techniques for selecting the samples for the study.

Sample size: 400

Development of tool: Based on objectives, a structured knowledge questionnaire was prepared to assess knowledge regarding inhalers.

Research Tool and Technique: Tools used for the study were structured knowledge questionnaire and 
structured educational programme. The purpose of the study was explained to the patients and question was given. Pre-test was conducted followed by structured educational programme. Post-test was done after two weeks of education session.

\section{FINDINGS}

Description of the study subjects according to their Demographic Characteristics:

The asthma patients attending in the outpatient department were described according to their demographic characteristics such as sex, age, religion, place of residence, education, occupation, income, marital status and diet. The percentage distribution was illustrated in the following mentioned Table -1

Table - 1: Description of Study Subjects in respect of their Demographic Characteristics $: \mathbf{N}=\mathbf{4 0 0}$

\begin{tabular}{|c|c|c|c|c|}
\hline SI. No. & Variables & Subject-groups & Number of persons $(N=400)$ & Percentage \\
\hline 1. & Age & $\begin{array}{l}<50 \text { years } \\
50 \text { years and above }\end{array}$ & $\begin{array}{l}189 \\
211\end{array}$ & $\begin{array}{l}47.2 \\
52.8\end{array}$ \\
\hline 2. & Gender & $\begin{array}{l}\text { Male } \\
\text { Female }\end{array}$ & $\begin{array}{l}212 \\
188 \\
\end{array}$ & $\begin{array}{l}53.0 \\
47.0\end{array}$ \\
\hline 3 & Religion & $\begin{array}{l}\text { Hindu } \\
\text { Christian } \\
\text { Muslim }\end{array}$ & $\begin{array}{l}174 \\
115 \\
111 \\
\end{array}$ & $\begin{array}{l}43.5 \\
28.7 \\
27.8\end{array}$ \\
\hline 4. & Place of Residence & $\begin{array}{l}\text { Village } \\
\text { Town } \\
\text { City }\end{array}$ & $\begin{array}{r}234 \\
161 \\
5 \\
\end{array}$ & $\begin{array}{r}58.5 \\
40.3 \\
1.3 \\
\end{array}$ \\
\hline 5. & Education & $\begin{array}{l}\text { Primary \& illiterate } \\
\text { Secondary } \\
\text { College } \\
\text { Professional Technical }\end{array}$ & $\begin{array}{r}87 \\
266 \\
31 \\
10\end{array}$ & $\begin{array}{r}29.0 \\
66.5 \\
7.8 \\
2.5 \\
\end{array}$ \\
\hline 6. & Occupation & $\begin{array}{l}\text { Unemployed } \\
\text { House wives } \\
\text { Coolie } \\
\text { Business } \\
\text { Office worker } \\
\text { Professional }\end{array}$ & $\begin{array}{r}6 \\
80 \\
230 \\
30 \\
38 \\
22 \\
\end{array}$ & $\begin{array}{r}1.5 \\
20.0 \\
57.5 \\
7.5 \\
9.5 \\
5.5 \\
\end{array}$ \\
\hline 7. & Monthly income & $\begin{array}{l}<1500 \\
1500-5000 \\
5001-10000 \\
10001 \text { and above } \\
\end{array}$ & $\begin{array}{r}16 \\
99 \\
214 \\
71 \\
\end{array}$ & $\begin{array}{r}4.0 \\
24.8 \\
21.7 \\
53.5 \\
\end{array}$ \\
\hline 8. & Marital status & $\begin{array}{l}\text { Married } \\
\text { Unmarried } \\
\text { Widow/ Widower } \\
\text { Divorced } \\
\end{array}$ & $\begin{array}{r}330 \\
38 \\
30 \\
2 \\
\end{array}$ & $\begin{array}{r}82.5 \\
9.5 \\
7.5 \\
5.0 \\
\end{array}$ \\
\hline 9 & Diet & $\begin{array}{l}\text { Vegetarian } \\
\text { Non-vegetarian }\end{array}$ & $\begin{array}{r}72 \\
328 \\
\end{array}$ & $\begin{array}{l}18.0 \\
82.0\end{array}$ \\
\hline
\end{tabular}

The above Table - 1 describes the study subjects in terms of their demographic variables. Almost two thirds $(52.8 \%)$ of subjects were above 50 years of age. Majority $(53 \%)$ of the patients were males and $47 \%$ of the patients were females. In respect of religion, Christians and Muslim were more or less equal (28.7\%) and (27.8\%). Majority (58.5\%) of the subjects belonged to villages. More than half $(66.5 \%)$ of the subjects were educated up to secondary education level. $40 \%$ were coolies by occupation. In respect of monthly income $53.5 \%$ of study subjects were living with family income of Rupees 10001 and above. $82.5 \%$ of the subjects were married. Majority of (82\%) the subjects had non-vegetarian diet habits. 
Assessment of Knowledge regarding Inhalers

Knowledge regarding inhalers was assessed before introduction of the structured educational programme.

Table - 2: Assessment of Knowledge regarding Inhalers

\begin{tabular}{|l|l|l|l|l|}
\hline SI. No. & Category & $\mathbf{n}$ & mean & S.D \\
\hline 1. & Pre-test & 400 & 14.40 & 3.641 \\
\hline
\end{tabular}

The Table - 2 shows knowledge regarding inhalers of study subjects. The mean knowledge was $14.40 \pm 3.641$ Effectiveness of Structured Educational Programme on Knowledge of Inhalers:

The effectiveness of structured educational programme was studied by comparing the pre- and post-test knowledge of study subjects. The results are tabulated as follows

Table - 3: Effectiveness of Structured Educational Programme

$N=400$

\begin{tabular}{|l|l|l|l|l|l|l|}
\hline Category & Mean & S.D & $\begin{array}{l}\text { Mean } \\
\text { differe } \\
\text { nce }\end{array}$ & 't' & df & Significance \\
\hline Pre-test & 14.40 & 3.641 & 4.91 & 45.6 & 399 & $P<0.01$ \\
\hline Post-test & 19.31 & 3.943 & & & \\
\hline
\end{tabular}

The Table - 3 shows the effectiveness of structured educational programme. The mean knowledge of the pretest was $14.40 \pm 3.641$ and the same was raised to $19.31 \pm 3.943$ with the introduction of the structured educational programme. The mean increase was statistically highly significant $(t=45.6, d f=399$ and $P<0.01)$.

\section{CONCLUSION}

Knowledge regarding inhalers was assessed before introduction of the structured educational programme. There is significant improvement in percentage of knowledge from pre-test to post-test after imparting structured educational programme.

\section{RECOMMENDATIONS}

- Similar study can be replicated with large samples.

- A comparative study can be conducted among patients with bronchial asthma in rural and urban population.

\section{REFERENCES}

1. Black J M, Haws J H. Medical Surgical Nursing clinical management for positive outcomes. $7^{\text {th }}$ ed. St. Louis, Missouri: Saunders.2005.

2. Lewis, S. L., Heitkemper, M.M., Dirksen, S.R., O’Brien, P.G., Bucher, L. Medical-Surgical Nursing assessment and management of clinical problems. $7^{\text {th }}$ ed. St. Louis, Missouri: Mosby. 2007.

3. Morton, P.G., Fontaine, D.K., Hudak, C.M., Gallo, B.M., Critical Care Nursing A holistic Approach $8^{\text {th }}$ ed.Lippincott Williams Wilkins

4. Sidney, S.B., The Global Burden of Asthma, Division of Pulmonary and Critical Care Medicine, Providence, RI. (2011).

5. Jindal, P. et al (2010) Prevalence of Asthma in Finnish young men, Department of allergic diseases, University Central Hospital, Finland.

6. Barua, Combined Corticosteroid and long acting beta-agonist in one inhaler for chronic obstructive pulmonary disease, Journal of allergy and clinical immunology 2009, Jan, 41(8): 111-117.

7. Tricia, B., Inhaler devices for the management of asthma and COPD. Centre for Reviews and Dissemination, Effective Health Care 2003, 8(1): 12-4.

8. Trautner, C. et al, An assessment of the value of health education in the prevention of childhood asthma, J Pulmonary medicine and therapeutics 1991, Dec, 20(3): 49-51.

9. Cochrane Importance of inhaler devices in the management of airway diseases. J Respiratory medicine 2009, Nov, 29(7): 203-205.

10. Kraut, D., A brief history of inhaled asthma therapy over the last sixty years. Primary care respiratory journal 2000,Mar, 31(3): 129-33

11. Ranjith Govind, V.S. et al Epidemiological study on genetics and environment of asthma. Clinical epidemiology 2000Sep, 38(1): 1415-41. 